\title{
ENGINEERING DESIGN AND LEARNING ACTIVITIES FOR GRADE 7 AND GRADE 8 SCIENCE AND TECHNOLOGY EDUCATION IN ONTARIO
}

\author{
Moresoli, C; Arnold, R, Moore, N, Van Lanen, D \\ Department of Chemical Engineering, University of Waterloo, Ontario Canada
}

cmoresol@uwaterloo.ca

\section{INTRODUCTION}

Interactive learning activities for the teaching of technology concepts represent an attractive approach to stimulate the interest of students for science and technology and engage the students in their learning. By being used in the classroom, these learning activities will reach the entire student population, students with a limited interest and students with a strong interest in science and technology. This is different than outreach activities typically held outside of the classroom that require an effort from the student and the family. This additional effort may end up attracting students already interested in science while leaving out students with limited or no interest in science and technology. Finally the learning activities had to be strongly connected to the curriculum to be attractive to teachers.

Our intention in this work was twofold. First, develop interactive learning activities for the teaching of technology concepts to Grade 7 and Grade 8 students. The activities had to be engaging, fun, and educational and stimulate an interest in students to learn more about science and technology. Second, enable first year undergraduate engineering students to acquire engineering design and communication skills.

\section{METHODS}

The interactive learning activities were designed and tested in Grade 7 or Grade 8 classes by first year undergraduate engineering students in partnership with science and technology teachers of the Waterloo region. The spiral engineering design approach as described by Andrews et al (1) was employed. A number of cycles of design, iteration, testing and modifications were carried out. The approach developed for the design of the learning activities is illustrated in Figure 1. Design requirements were established and included the teaching of concepts outlined in the Ontario Science and Technology Curriculum (2); be engaging and fun; easy to use. Design constraints were identified: maximum total cost of $\$ 50.00$ for a class of 30 students and time constraint as multiple 40 minutes class period. The second step was to identify potential activities and themes for a given unit of the Ontario Grade 7 and Grade 8 Science and Technology curriculum (2). The third and subsequent steps were to design the learning activity and prepare a student's guide, teacher's guide and assessment tool (pre and post-knowledge test and a learning assessment test).

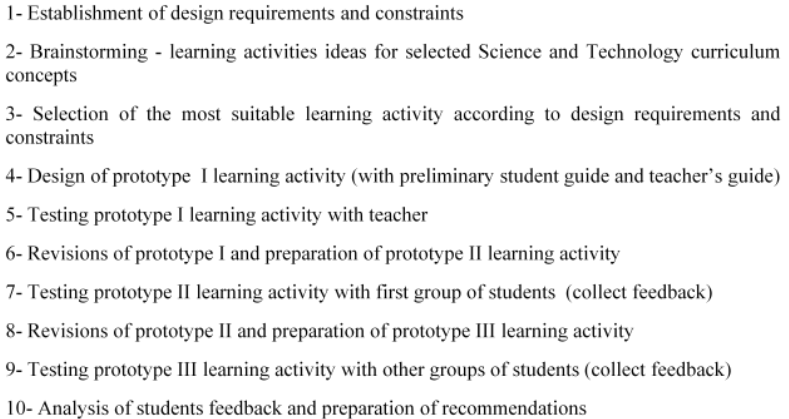

Figure 1: Details of the design approach for the development of learning activities for the teaching of Grade 7 and 8 Science and Technology curriculum concepts.

\section{DISCUSSION}

To date, three different learning activities have been designed and are available for teacher's use. Each learning activity was designed, tested and analyzed by a first year undergraduate chemical engineering student over a four month co-op work term taking place from January to April according to the method presented in Figure 1. The first month was devoted to step 1-4. The second and third month were devoted to step 59. The fourth and last month was devoted to step 10 .

The communications between the undergraduate engineering student and the teacher was achieved by email and face to face meetings. The undergraduate student learned how to describe clearly and concisely the learning activity and his plans for in class testing of the activity.

The potential ideas for a learning activity were generated by reading the specific unit of the Ontario Science and Technology Curriculum identified by the teacher and any other resources such as the web, scientific publications.

The most promising idea for a learning activity was identified according to the design requirements and constraints (described previously in the methods section). The next step was the design of prototype I learning activity and arrange for a meeting with the teacher, visit the classroom and obtain feedback on prototype 1 learning activity.

The actual implementation of the learning activity (prototype II and prototype III) consisted of sequentially testing the learning activity with three classes of Grade 7 or Grade 8 students at the same school and with the same teacher. In this phase, the undergraduate engineering student developed communication skills adapted to Grade 7 or Grade 8 student audience with diversified ability and interest in science and technology. Modifications that were made to the learning activity included clarity of the instructions and scope of the learning activity.

The pre- and post-tests had the same questions and consisted of ten (10) multiple choice questions on specific science and technology concepts associated with the learning activity. For example, the learning activity developed on the unit 'Understanding Structures and Mechanisms' (1) included questions related to force, work and machines. The results for each individual question, before and after the learning activity, were compared using the average and standard deviation.

The learning assessment test included four specific questions (answers on a scale of one (1- did not enjoy the activity) to five (5- really enjoyed the activity)) and two open ended questions. The results of the learning assessment test indicated that the students enjoyed the activity, felt that the instructions were clear and that they learned from the activity.

This program was successful in enabling first year undergraduate engineering students to acquire communication, design and planning skills in their first work term and in showing that science and technology can be fun while learning.

\section{ACKNOWLEDGEMENTS}

Financial support from NSERC CRYSTAL Centre at Universite de Sherbrooke, the Faculty of Engineering at University of Waterloo and the Centre for the Control of Emerging Contaminants and technical support from Engineering Science Quest (ESQ) at University of Waterloo are acknowledged.

\section{REFERENCES}

1. Ontario: Ministry of Education. Science and Technology: The Ontario Curriculum Grades 1-8., 2007.

2. Andrews G, Aplevich J, Fraser R, Macgregor C, and Ratz H, Introduction to Professional Engineering in Canada. Toronto: Pearson Education Canada Inc., 2006, pp. 36-38. 